\title{
Overtopping Risk Analysis of Earth Dams considering Effects of Failure Duration of Release Structures
}

\author{
Lijun Liu ${ }^{1}$ and Zhenyu Wu $\mathbb{D}^{2,3}$ \\ ${ }^{1}$ Survey and Design Institute, Guangdong Research Institute of Water Resources and Hydropower, \\ No. 116 Tianshou Road, Tianhe District, Guangzhou 510635, China \\ ${ }^{2}$ State Key Laboratory of Hydraulics and Mountain River Engineering, Sichuan University, No. 24 South Section 1, Yihuan Road, \\ Chengdu 610065, China \\ ${ }^{3}$ College of Hydraulic and Hydroelectric Engineering, Sichuan University, No. 24 South Section 1, Yihuan Road, \\ Chengdu 610065, China
}

Correspondence should be addressed to Zhenyu Wu; scuwzy@qq.com

Received 19 May 2020; Accepted 20 July 2020; Published 12 August 2020

Academic Editor: Qingdu Li

Copyright (C) 2020 Lijun Liu and Zhenyu Wu. This is an open access article distributed under the Creative Commons Attribution License, which permits unrestricted use, distribution, and reproduction in any medium, provided the original work is properly cited.

\begin{abstract}
For modern high earth dams, sufficient safety margin is considered in the designs of flood discharge capacity and dam crest elevation to prevent flood overtopping. However, for high earth dams which may induce catastrophic consequences, during their long operational period, extremely hazardous scenarios which could occur and threaten dam safety need to be considered. For the earth dams located in areas with intensive seismicity, there is a possible scenario that the release structures fail due to seismic landslides and gate failures caused by a severe earthquake when the flood begins to enter the reservoir. Thus, it is desirable to investigate the influence of failure duration of release structures on dam overtopping risk. Based on the Bayesian network, a methodology for overtopping risk analysis of earth dams considering effects of failure duration of release structures is proposed. The overtopping risk of the PBG earth-rockfill dam was analyzed to illustrate the methodology. The critical release structures which dominate the dam overtopping risk are identified. The dam overtopping risk is most sensitive to the failure duration of the spillway. The tolerable failure duration of the spillway is approximately 3 days, and when the failure duration of the spillway reaches 4 days, the dam overtopping risk drastically rises to an unacceptable level. The case study suggests that the proposed methodology could be helpful to analyze the influences of possible failure durations of release structures on dam overtopping risk and could facilitate preparation for emergency plans.
\end{abstract}

\section{Introduction}

Dams are important infrastructures for water resources management. There are more than 98000 dams in China, among which earth dams are more than 80000 [1]. Dam breaks have occurred frequently in the past 100 years and have caused huge losses of life and property [2]. Overtopping is one of the main causes of the earth dam break [3-5]. Overtopping risk analysis could provide useful information for decision making on reservoir operation and dam safety management.

Numerous research works on risk analysis of dam overtopping have been reported in the literature. As regards the uncertainties in overtopping risk analysis, the effects of uncertainties in flood, reservoir characteristics, outflow discharge, initial water surface level, wind velocity, dam height, and so on have been well investigated (e.g., [6-13]). Regarding approaches for overtopping risk analysis, a variety of approaches have been applied, such as stochastic differential equations (e.g., [14]), bivariate copula functions (e.g., [15-17]), sequential uncertainty fitting method (e.g., [18]), Latin hypercube sampling (e.g., $[19,20]$ ), maximum entropy method (e.g., [21]), and Bayesian network (e.g., [22-24]).

In order to obtain hydropower, many high earth dams have been built in western China. Sufficient safety margin is 
considered in the designs of flood discharge capacity and dam crest elevation to prevent flood overtopping. In addition, the water level of the reservoir in flood season shall not exceed the specified limit water level. Therefore, the safety of the dams can be guaranteed even for the possible maximum flood. However, in western China, the occurrence frequency and intensity of earthquakes are high. Strong earthquakes may trigger massive rockfalls and landslides around the dams. For instance, the Wenchuan earthquake in 2008 caused more than 200000 landslides [25-27]. The deposits formed by rockfalls or landslides may block release structures. And the gates of the release structures may not be opened due to excessive seismic distortion. For example, the landslides induced by the Wenchuan earthquake buried the inlet and/or outlet of the release structures of the Yuzixi, Yingxiuwan, and Taipingyi hydropower stations. The earthquake led to a temporary malfunction of the flood discharge gates of the Taipingyi, Futang, Jiangsheba, and Gengda sluices.

Therefore, although the overtopping risk of the dams under normal operating conditions is quite small, if an extremely strong earthquake in the flood season leads to failure of the release structures and the flood discharge function of the release structures cannot be restored in time, dam overtopping may occur. Thus, for the earth dams located in areas with intensive seismicity, especially in the flood season, it is necessary to consider the impact of the failure of release structures caused by seismic landslides on dam overtopping risk. The important effect of the unavailability of the spillway on dam overtopping risk has been investigated (e.g., [28-31]). In fact, the flood discharge capability of the failed release structures has to be recovered as quickly as possible. Hence, the influence of the failure duration of release structures on dam overtopping risk is worth being investigated. Based on the Bayesian network, a methodology for overtopping risk analysis of earth dams considering effects of failure duration of release structures is proposed in this paper. A case study is presented to illustrate the methodology.

\section{Methodology for Overtopping Risk Analysis considering Failure Duration of Release Structures}

2.1. Outline of the Overtopping Risk Analysis. In this paper, the scenario for overtopping risk analysis of earth dams is supposed as follows: when a flood begins to enter the reservoir, a strong earthquake occurs near the dam site. The earthquake may cause landslides around the dam and the resulting deposits may block the release structures, such as spillway and flood discharging tunnel. In addition, the gates of the release structures may fail to open due to the seismic action. Although emergency measures are taken to recover the discharge capability of the release structures, before discharge capability recovery, the failure duration of the respective release structure should increase the dam overtopping risk.
For simplicity, the probabilistic seismic hazard is not addressed in this study. It is assumed that a strong earthquake definitely occurs near the dam site and the intensity of the earthquake is adequately large so that it is possible to induce landslides. Additionally, since this study focuses on the effects of failure duration of release structures on dam overtopping risk and the effects of uncertainties in other affecting factors (such as flood, reservoir characteristics, initial water surface level, and dam height) have been well investigated as mentioned above, only the uncertainties in seismic landslides, gate failure, and failure duration of release structures are considered in the analysis.

Dam overtopping is the result of a series of uncertain events (event chain) with cascading causality. For example, an earthquake occurs when a flood is entering a reservoir, the earthquake causes landslides, subsequently, the landslide deposits block the spillway, the discharge capability of the spillway cannot be restored timely, and then dam overtopping happens. For practical problems, multiple overtopping event chains may exist. In this study, the Bayesian network (i.e., a directed acyclic graph composed of nodes and directed arcs) is adopted to characterize complex chains of overtopping event. In the Bayesian network, the probability of occurrence of an event represented by a node (child node) can be calculated by conditional probability formula in terms of the probabilities of occurrence of events represented by the parent nodes of the child node [32].

Suppose that an earth dam hub has $M$ release structures and there are $N_{i}$ seismic landslides that may lead to failure of the $i$ th release structure. In addition, gate failure may also result in failure of the release structure. Figure 1 shows the Bayesian network model of overtopping risk analysis for earth dams in this study. The procedure of overtopping risk analysis is as follows:

(a) According to the topographical and geological conditions as well as the layout of release structures for a specific earth dam hub, potential seismic landslides and the release structures which may be affected by the landslides are determined. Then, the Bayesian network as shown in Figure 1 is established.

(b) Estimating the probabilities of seismic landslide and gate failure: The method adopted in this study is detailed in Section 2.2.

(c) The failure duration of release structure related to a seismic landslide or gate failure is treated as a random variable with uniform or triangular distribution, and the relevant distribution parameters are estimated by experts. The probability distribution of failure duration of a release structure which may be affected by multiple landslides and gate failure is determined in terms of the probability distributions of failure duration associated with the landslides and gate failure, as well as the probabilities of occurrence of the combinations of the landslides and gate failure. A detailed description is given in Section 2.3.

(d) Considering the influence of failure durations of the release structures, reservoir routings are 
implemented and the conditional probabilities of dam overtopping are determined. The details of the computing process are presented in Section 2.4

(e) The probability of dam overtopping is computed with the Bayesian network, given the probabilities of seismic landslides and gate failures, the probability distributions of failure duration of the release structures, and the conditional probabilities of overtopping corresponding to the given inflow hydrograph and the failure durations of the release structures.

\subsection{Estimation of Probabilities of Seismic Landslide and Gate} Failure. The probabilities of seismic landslide and gate failure can be quantitatively calculated using the reliability analysis method (e.g., [33-35]). Due to the difficulties in the characterization of the probability distributions for material properties and loads, as well as the complexity of the computation process, the application of probabilistic methods in practical problems is still limited.

The methods for estimation of probabilities of seismic landslide and gate failure are beyond the scope of the paper, and the results of the probability estimation do not affect the implementation of the methodology for overtopping risk analysis. For simplicity, the method presented by [36] is used to estimate the probabilities of seismic landslide and gate failure. The procedure is as follows.

First, the seismic stabilities of the slopes and the seismic resistance of the gates that may affect the release structures are ranked by expert judgment. Then, the linguistic descriptions of the likelihood of landslide and gate failure under strong earthquakes are presented. Finally, according to the prescribed probabilities corresponding to the linguistic descriptions of likelihood (as shown in Table 1), the probabilities of seismic landslide and gate failure are determined.

\subsection{Probability Distribution of Failure Duration of Release} Structure. For scarce knowledge and historical data for failure duration of release structure (especially for a specific project) affected by seismic landslide and gate failure after a strong earthquake, in this study, the probability distribution of failure duration of release structure related to a landslide or gate failure is assumed to follow uniform distribution or triangular distribution [37] and the relevant distribution parameters are estimated by experts.

The uniform distribution for failure duration of release structure is as follows:

$$
f(T)=\frac{1}{T_{\max }-T_{\min }}, \quad \text { for } \quad T_{\min } \leq T \leq T_{\max },
$$

where $T_{\min }$ and $T_{\max }$ are the lower and upper limits of the failure duration $T$.

The triangular distribution for failure duration of release structure is expressed as

$$
f(T)= \begin{cases}\frac{2\left(T-T_{\min }\right)}{\left(T_{\max }-T_{\min }\right)\left(T_{\mathrm{mlv}}-T_{\min }\right)}, & \text { for } \quad T_{\min } \leq T \leq T_{\mathrm{mlv}}, \\ \frac{2\left(T_{\max }-T\right)}{\left(T_{\max }-T_{\min }\right)\left(T_{\max }-T_{\mathrm{mlv}}\right)}, & \text { for } \quad T_{\mathrm{mlv}}<T \leq T_{\max },\end{cases}
$$

where $T_{\mathrm{mlv}}$ is the most likely value of $T$.

For a release structure which may be affected by multiple landslides and gate failure, the probability distribution of failure duration of the release structure is determined in terms of the probability distributions of failure duration related to the landslides and gate failure, as well as all possible combinations of the landslides and gate failure and associated probabilities. For the case where multiple landslides and gate failure simultaneously occur, it is assumed that only the probability distribution of failure duration with the largest values of $T_{\min }$ and $T_{\max }$ is considered.

For instance, suppose a release structure which may be affected by two landslides (denoted by LS1 and LS2) and gate failure (denoted by GF); the probabilities of LS1, LS2, and GF are $P(\mathrm{LS} 1), P(\mathrm{LS} 2)$, and $P(\mathrm{GF})$, respectively; the probability distributions of failure duration related to LS1, LS2, and GF are $f_{\mathrm{LS} 1}(T), f_{\mathrm{LS} 2}(T)$, and $f_{\mathrm{GF}}(T)$, respectively; in addition, $f_{\mathrm{LS} 1}(T)$ and $f_{\mathrm{GF}}(T)$ have the largest and smallest values of $T_{\min }$ and $T_{\max }$, respectively. Thus, the probability distribution of failure duration of the release structure is determined as $f(T)=f_{\mathrm{LS} 1}(T) \times P(\mathrm{LS} 1) \times P(\mathrm{LS} 2) \times \mathrm{P}(\mathrm{GF})+$ $\mathrm{fLS1}(\mathrm{T}) \times \mathrm{P}(\mathrm{LS} 1) \times[1-\mathrm{P}(\mathrm{LS} 2)] \times \mathrm{P}(\mathrm{GF})+\mathrm{fLS} 1(\mathrm{~T}) \times \mathrm{P}(\mathrm{LS} 1) \times$ $\mathrm{P}(\mathrm{LS} 2) \times[1-\mathrm{P}(\mathrm{GF})]+\mathrm{fLS} 1(\mathrm{~T}) \times P(\mathrm{LS} 1) \times[1-P(\mathrm{LS} 2)] \times[1-$ $P(\mathrm{GF})]+f_{\mathrm{LS} 2}(T) \times[1-P(\mathrm{LS} 1)] \times P(\mathrm{LS} 2) \times P(\mathrm{GF})+f_{\mathrm{LS} 2}(T) \times$ $[1-P(\mathrm{LS} 1)] \times P(\mathrm{LS} 2) \times[1-P(\mathrm{GF})]+f_{\mathrm{GF}}(T) \times[1-P(\mathrm{LS} 1)] \times$ $[1-P(\mathrm{LS} 2)] \times P(\mathrm{GF})$ and $f(T=0)=[1-P(\mathrm{LS} 1)] \times[1-P(\mathrm{LS} 2)] \times$ $[1-P(\mathrm{GF})]$

\subsection{Reservoir Routing considering Failure Duration of Release} Structure and Conditional Probability of Dam Overtopping. In the course of reservoir routing, the water level in the reservoir rises as the outflow through release structures is less than the inflow. When the water level exceeds the dam crest, the dam overtopping occurs. Given the water levelstorage capacity curve, the flood hydrograph, and the discharge curve for release structures, the water level in the reservoir can be determined by solving the water balance equation [23]. In reservoir routing, the discharge of a failed release structure is set to be null until its functionality is recovered. An illustrative example of reservoir routing considering failure duration of release structure is presented as follows.

Assume that an earth dam hub has $n$ release structures (RS1, RS2, ..., RSn). When a flood begins to enter the reservoir, all the release structures fail due to a strong earthquake; the failure duration of each release structure is $0<t_{1}<t_{2}<\cdots<t_{n}$; the corresponding reservoir routing is shown in Figure 2. During $0 \leq t<t_{1}$, all the release structures do not participate in flood discharge, so that the total discharge $q=0$. During $t_{1} \leq t<t_{2}$, only the discharge capability 


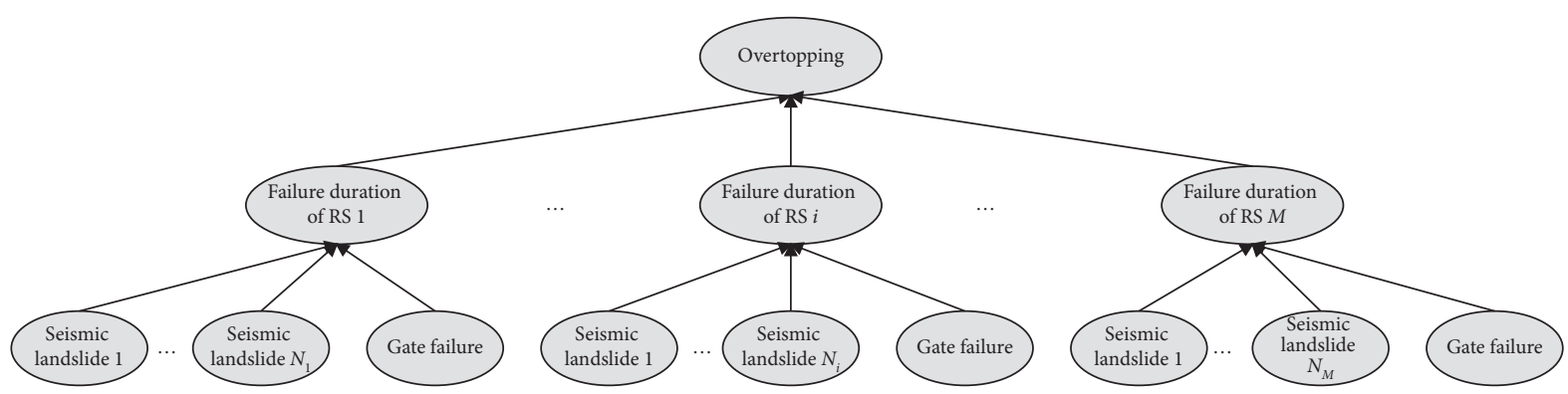

FIGURE 1: Bayesian network for overtopping risk analysis of earth dams considering failure duration of release structures.

TABle 1: Probabilities corresponding to linguistic description of likelihood.

\begin{tabular}{lc}
\hline Linguistic description & Probability of occurrence \\
\hline Very likely & 0.95 \\
Highly likely & 0.9 \\
Likely & 0.8 \\
Fairly likely & 0.65 \\
Even & 0.5 \\
Fairly unlikely & 0.35 \\
Unlikely & 0.2 \\
Highly unlikely & 0.1 \\
Very unlikely & 0.05 \\
\hline
\end{tabular}

of the release structure RS1 is recovered; thus, $q=q_{1}, q_{1}$ is the discharge of the release structure RS1. During $t_{2} \leq t<t_{3}$, the discharge capability of the release structure RS2 is recovered; hence, $q=q_{1}+q_{2}, q_{2}$ is the discharge of the release structure RS2. When $t>t_{n}$, the release structures all recover discharge capabilities; therefore, $q=q_{1}+q_{2}+\cdots+q_{n}$. The illustrative example demonstrates the case where the failure duration of the release structure is different for each other. For the case where a part of or all of the release structures have identical failure duration, the reservoir routing process is similar. If a release structure does not fail, the corresponding failure duration is defined as zero during reservoir routing.

Assume that there are $n$ release structures, for each of which $m$ failure durations are considered in reservoir routing. Thus, there are $m^{n}$ combinations of failure durations of the release structures for reservoir routing. Given flood hydrograph and a combination of failure durations of the release structures, the water level $H_{R}\left(t_{1}, t_{2}, \ldots, t_{n}\right)$ can be determined by reservoir routing and the corresponding conditional probability of dam overtopping is expressed as

$P_{o t}\left(t_{1}, t_{2}, \ldots, t_{n}\right)=\left\{\begin{array}{lll}1, & \text { if } & H_{R}\left(t_{1}, t_{2}, \ldots, t_{n}\right)>H_{C} \\ 0, & \text { if } & H_{R}\left(t_{1}, t_{2}, \ldots, t_{n}\right) \leq H_{C}\end{array}\right.$

where the failure durations of the release structures are represented by $t_{1}, t_{2}, \ldots, t_{n}$, and $H_{C}$ is the dam crest elevation.

\section{Case Study}

3.1. Brief Introduction of the PBG Hydropower Station. The PBG hydropower station is located on the Dadu River in Sichuan Province, China. The Dadu River is cut off by an

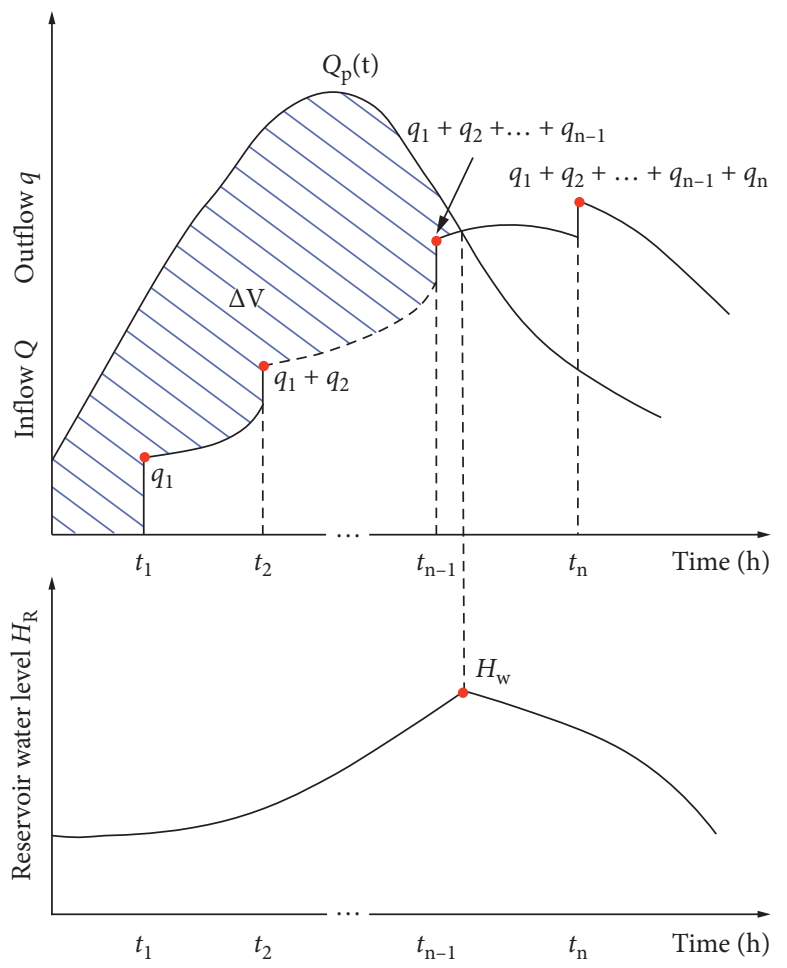

FIgURE 2: An illustrative example of reservoir routing considering failure duration of release structure.

earth-rockfill dam. A spillway, a flood discharging tunnel, and a power station diversion tunnel are arranged in the left bank, and an emptying tunnel is arranged in the right bank. The dam crest elevation is $856.00 \mathrm{~m}$, and the maximum dam height is $186 \mathrm{~m}$. The normal water level of the reservoir is $850.00 \mathrm{~m}$, the limited water level in flood season is $841.00 \mathrm{~m}$, the dead water level is $790.00 \mathrm{~m}$, and the total storage capacity is 5.337 billion $\mathrm{m}^{3}$. The layout of the hydropower station is shown in Figure 3.

The annual average temperature in the Dadu River basin is $13 \sim 18^{\circ} \mathrm{C}$, and the annual rainfall is $1400 \sim 1700 \mathrm{~mm}$. The rainfall in the wet season, from May to October, accounts for $80 \% \sim 90 \%$ of the annual rainfall, and the maximum daily rainfall is more than $100 \mathrm{~mm}$, even more than $400 \mathrm{~mm}$. Floods in the Dadu River are mainly formed by precipitation, and the annual maximum flood peak generally occurs in flood season (from June to September). A typical flood 


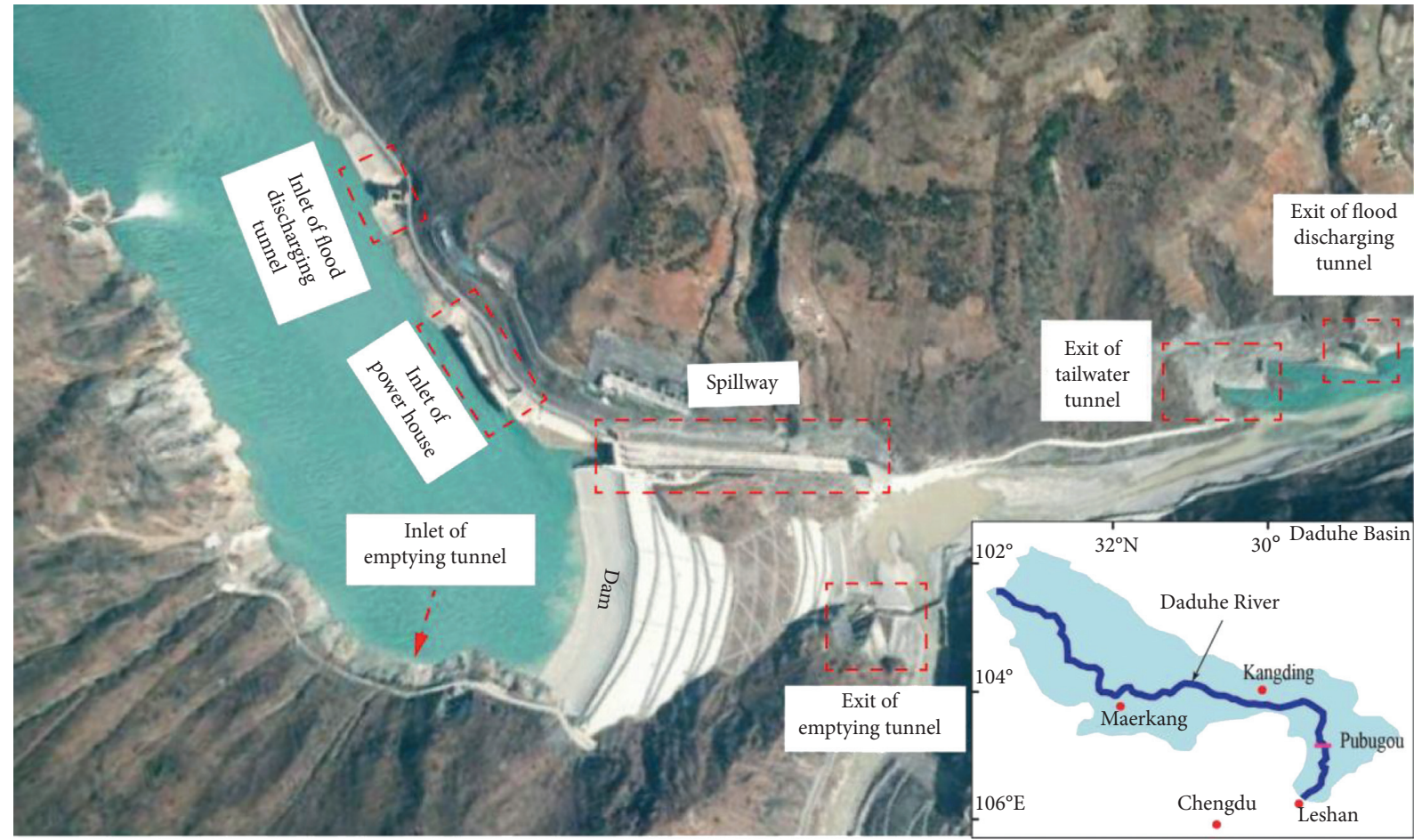

FIgure 3: The layout of the PBG hydropower station.

process lasts for about 15 days, in which the flood volume in 7 days accounts for more than $53 \%$ of the total flood volume, the flood volume in 3 days accounts for more than $48 \%$ of the flood volume in 7 days, and the flood volume in 1 day accounts for more than $35 \%$ of the flood volume in 3 days. The maximum flood peak which had been observed at the dam site is $8520 \mathrm{~m}^{3} / \mathrm{s}$.

Several large-scale active faults are distributed around the hydropower station, as shown in Figure 4. The PBG hydropower station is located in the block delimited by the faults. The historical earthquakes around the PBG hydropower station are shown in Figure 5. According to the probabilistic seismic hazard analysis, the probability of occurrence of earthquakes with a magnitude of more than 7.5 near the dam site is $0.23 \%$ in the next 50 years. And the peak value of horizontal acceleration at the dam site with an exceedance probability of $1 \%$ in the next 100 years is $0.48 \mathrm{~g}$.

3.2. Bayesian Network Model for Overtopping Risk Analysis of the PBG Dam. The release structures of the PBG hydropower station include spillway, flood discharging tunnel, power station diversion tunnel, and emptying tunnel. As mentioned above, severe earthquakes are quite likely to occur in the area near the PBG hydropower station in the future. Although the excavation slopes of the release structures have been reinforced, the natural slopes above the excavation slopes may slide under the action of a strong earthquake, and the landslides may result in failures of the release structures. For risk assessment, an extreme case is assumed that the PBG hydropower station would simultaneously encounter a strong earthquake and a big flood.
Considering the influences of seismic landslide and gate failure on the release structures of the PBG hydropower station and the failure durations of the release structures, a Bayesian network model for overtopping risk analysis of the earth-rockfill dam is established, as shown in Figure 6.

\subsection{Model Quantification}

3.3.1. Probabilities of the Seismic Landslides and Gate Failures. The method described in Section 2.2 is used to estimate the probabilities of the seismic landslides that may affect the release structures. First, the stabilities of the natural slopes above the release structures under a strong earthquake are ranked by expert judgment, then the likelihoods of seismic landslides are described with linguistic description, and finally, the probabilities of seismic landslides are determined in terms of the probabilities related to the linguistic descriptions of likelihood (see Table 1). The probabilities of gate failures induced by an earthquake are estimated similarly. Tables 2 and 3 show the ranks of slope stability and the ranks of seismic resistance of the gates, together with the linguistic descriptions of the likelihood of seismic landslide and gate failure, while the corresponding probabilities are listed in Table 4.

\subsubsection{Estimation of Probability Distribution Parameters for} Failure Duration of Release Structure. For comparison, the probability distribution of failure duration of release structure related to a landslide or gate failure is assumed to follow the uniform distribution and triangular distribution. The probability distribution parameters $T_{\min }$ (the lower limit 


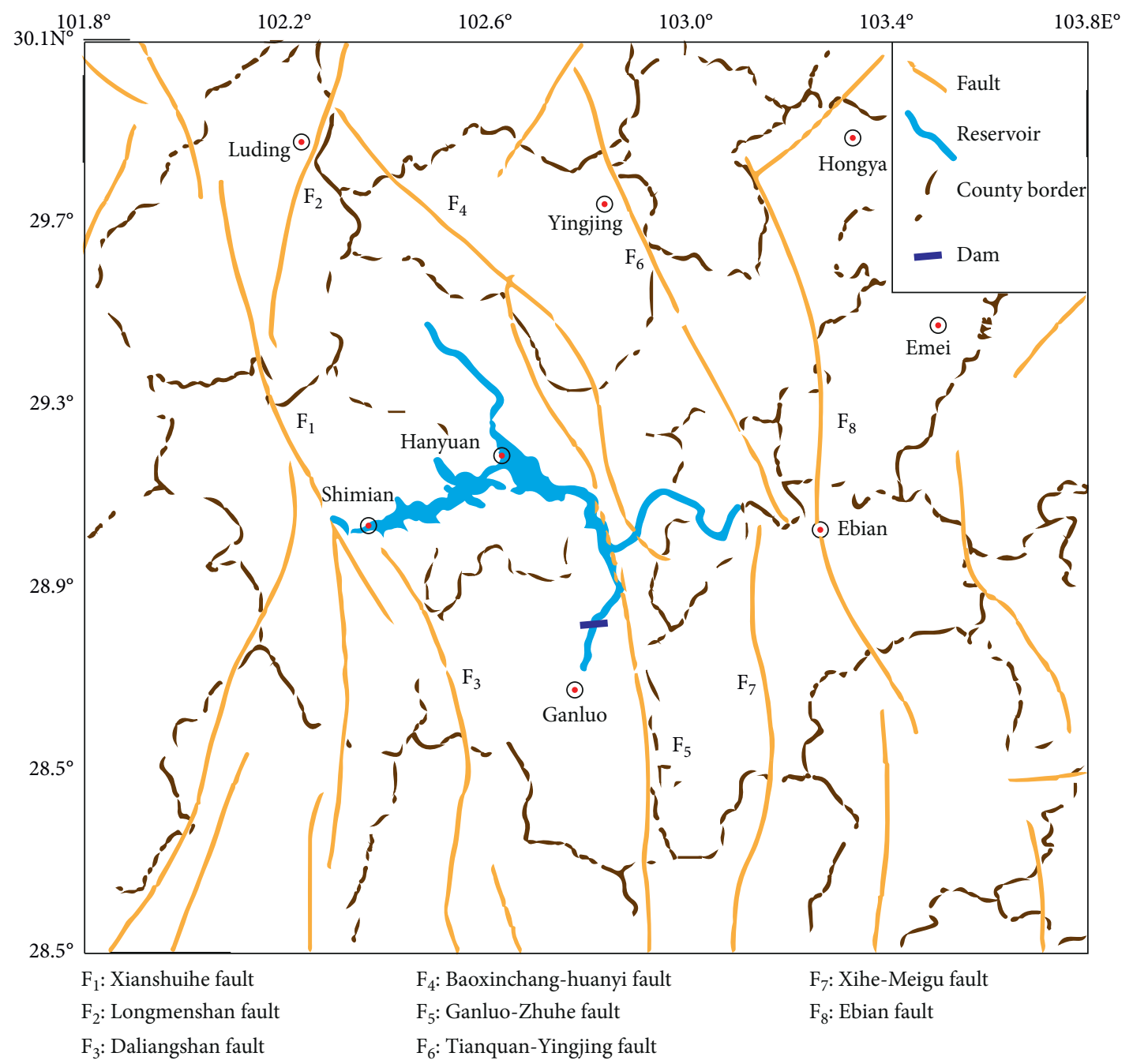

Figure 4: Large-scale faults around the PBG hydropower station.

of failure duration), $T_{\max }$ (the upper limit of failure duration), and $T_{\text {mlv }}$ (the most likely value of failure duration) are estimated by experts and are listed in Table 5 .

\subsubsection{Reservoir Routing and Determination of Conditional} Probability of Dam Overtopping. The maximum design flood hydrograph for the PBG hydropower station is shown in Figure 7. The flood process lasts 392 hours, and the flood peak appears on the 8 th day, which is $15250 \mathrm{~m}^{3} / \mathrm{s}$. The water level-storage capacity curve and the discharge curve for release structures are shown in Figures 8 and 9, respectively.

It is assumed that when the flood begins to enter the reservoir (the water level of the reservoir is keeping as $841.00 \mathrm{~m}$ in flood season), a severe earthquake occurs, and the resultant landslides and gate failures subsequently cause failures of the release structures. Considering the influence of failure durations of the release structures, the method presented in Section 2.4 is used to compute the maximum water level in the course of reservoir routing. In order to reduce the computational effort, discrete failure duration (i.e., $0 \mathrm{~d}, 1 \mathrm{~d}, \ldots, 16 \mathrm{~d}$ ) is adopted in reservoir routing.
Therefore, the total number of reservoir routings is $m^{n}=17^{4}=83521$, where $m$ is the number of failure durations and $n$ is the number of release structures. According to the results of 83521 reservoir routings, the conditional probabilities of dam overtopping are determined using Equation (3).

Figure 10 shows two typical results of reservoir routing: (a) the failure durations of the spillway, flood discharging tunnel, power station diversion tunnel, and emptying tunnel are $1 \mathrm{~d}, 3 \mathrm{~d}, 5 \mathrm{~d}$, and $7 \mathrm{~d}$, respectively, the corresponding maximum water level $H_{R}$ is lower than the dam crest elevation $H_{C}\left(H_{C}=856.00 \mathrm{~m}\right)$, and thus, dam overtopping does not occur; (b) the failure durations of the spillway, flood discharging tunnel, power station diversion tunnel, and emptying tunnel are $7 \mathrm{~d}, 5 \mathrm{~d}, 3 \mathrm{~d}$, and $1 \mathrm{~d}$, respectively; in this case, dam overtopping occurs on the 4 th day of the flood process.

\section{Results and Discussion}

For the case where the probability distribution of failure duration of release structure related to a landslide or gate 


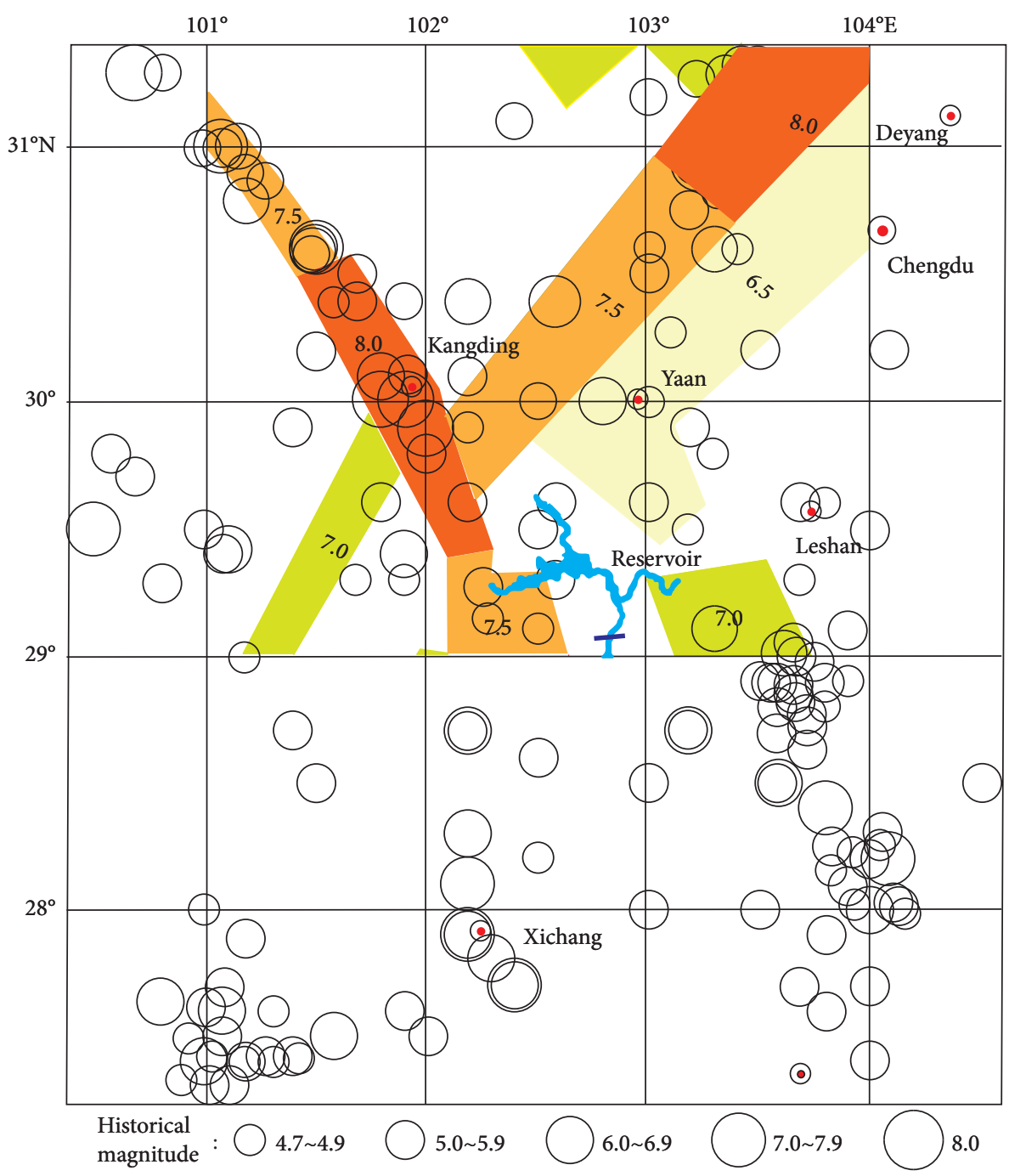

The color stripe is the potential earthquake source region, and the number is the magnitude of the potential earthquake.

FIGURE 5: The historical earthquakes around the PBG hydropower station.

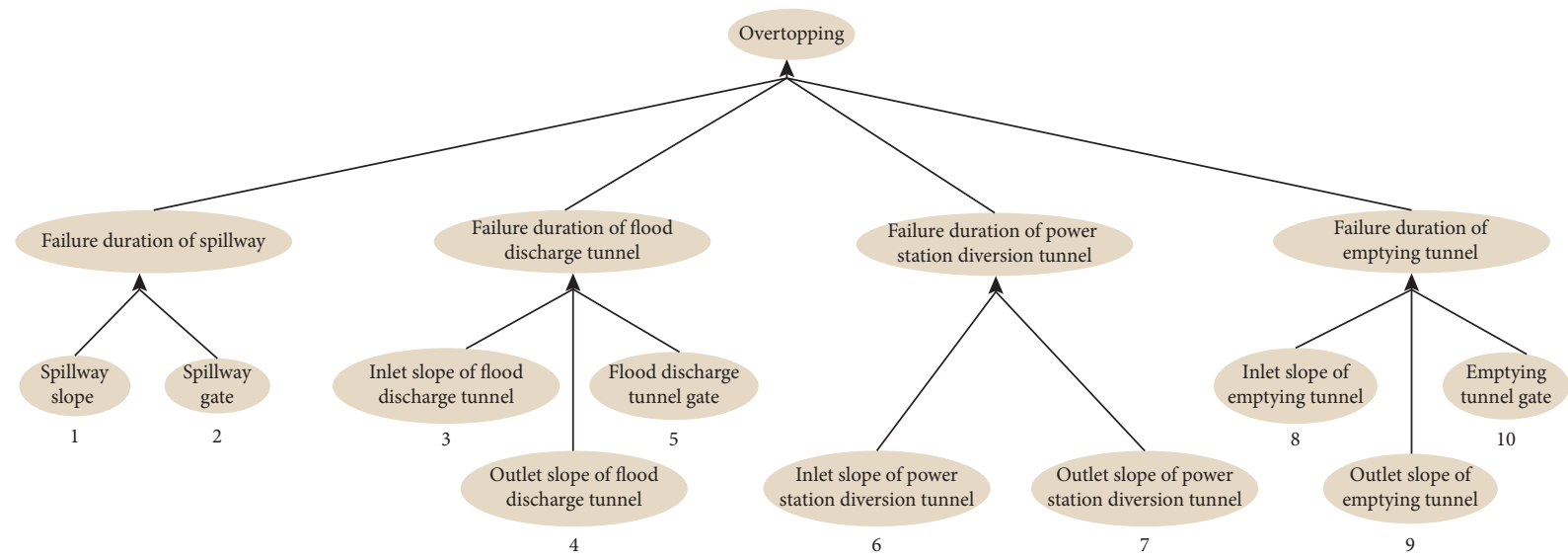

FIGURE 6: Bayesian network model for overtopping risk analysis of the PBG dam. 
TABle 2: Ranks of slope stability and linguistic descriptions of the likelihood of a seismic landslide.

\begin{tabular}{|c|c|c|c|}
\hline Slope & Brief description of slope & $\begin{array}{l}\text { Stability } \\
\text { rank }\end{array}$ & $\begin{array}{c}\text { Likelihood of } \\
\text { seismic landslide }\end{array}$ \\
\hline Spillway slope & $\begin{array}{l}\text { The dip angle of the slope is } 35^{\circ} \sim 45^{\circ} \text {. The slope is mainly composed of } \\
\text { gravelly soils and weathered unloading rocks. }\end{array}$ & 3 & Fairly likely \\
\hline $\begin{array}{l}\text { Inlet slope of flood } \\
\text { discharging tunnel }\end{array}$ & $\begin{array}{l}\text { The dip angle of the slope is } 30^{\circ} \sim 40^{\circ} \text {. The slope is mainly composed of } \\
\text { colluvial gravelly soils. }\end{array}$ & 2 & Even \\
\hline $\begin{array}{l}\text { Outlet slope of flood } \\
\text { discharging tunnel }\end{array}$ & $\begin{array}{l}\text { The average dip angle of the slope is } 55^{\circ} \text {. The unloading effect of the } \\
\text { superficial rocks is quite significant, which results in the tensile } \\
\text { deformation of the rocks. The aperture of rock fracture is } 1 \sim 4 \mathrm{~cm} \text { wide. }\end{array}$ & 5 & Highly likely \\
\hline $\begin{array}{l}\text { Inlet slope of power station } \\
\text { diversion tunnel }\end{array}$ & The slope is rather steep and consists of colluvial gravelly soils. & 3 & Fairly likely \\
\hline $\begin{array}{l}\text { Outlet slope of power station } \\
\text { diversion tunnel }\end{array}$ & $\begin{array}{l}\text { The slope is steep and mainly consists of weakly weathered and unloading } \\
\text { rocks. There is a significantly unloading rock mass at an elevation of } 875 \mathrm{~m} \text {, } \\
\text { part of which had collapsed and buried the tailwater outlet. }\end{array}$ & 6 & Very likely \\
\hline $\begin{array}{l}\text { Inlet slope of the emptying } \\
\text { tunnel }\end{array}$ & $\begin{array}{l}\text { The dip angle of the slope is } 35^{\circ} \sim 50^{\circ} \text {. The slope is mainly composed of } \\
\text { colluvial gravelly soils. The slope had largely deformed. }\end{array}$ & 4 & Likely \\
\hline $\begin{array}{l}\text { Outlet slope of the emptying } \\
\text { tunnel }\end{array}$ & The slope is gentle and mainly consists of weakly weathered rocks. & 1 & Unlikely \\
\hline
\end{tabular}

TABLE 3: Ranks of seismic resistance of gate and linguistic descriptions of the likelihood of gate failure.

\begin{tabular}{|c|c|c|c|}
\hline Gate & Brief description of the gate & $\begin{array}{l}\text { Seismic resistance } \\
\text { rank }\end{array}$ & $\begin{array}{l}\text { Likelihood of } \\
\text { gate failure }\end{array}$ \\
\hline Spillway gate & $\begin{array}{l}\begin{array}{l}\text { The gate is located on the left bank and is susceptible to seismic loading } \\
\text { and rockfall. }\end{array}\end{array}$ & 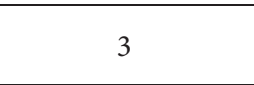 & Fairly likely \\
\hline $\begin{array}{l}\text { Flood discharging tunnel } \\
\text { gate }\end{array}$ & $\begin{array}{c}\text { The gate is located in the inlet of the flood discharging tunnel and is } \\
\text { submerged. }\end{array}$ & 2 & Even \\
\hline Emptying tunnel gate & $\begin{array}{l}\text { The gate is located in the inlet of the emptying tunnel and is submerged } \\
\text { deeply in the reservoir. }\end{array}$ & 1 & Unlikely \\
\hline
\end{tabular}

TABle 4: Probabilities of seismic landslides and gate failures.

\begin{tabular}{lcc}
\hline Node number & Node name & Failure probability \\
\hline 1 & Spillway slope & 0.65 \\
2 & Spillway gate & 0.65 \\
3 & Inlet slope of flood discharging tunnel & 0.5 \\
4 & Outlet slope of flood discharging tunnel & 0.9 \\
5 & Flood discharging tunnel gate & 0.5 \\
6 & Inlet slope of power station diversion tunnel & 0.65 \\
7 & Outlet slope of power station diversion tunnel & 0.95 \\
8 & Inlet slope of the emptying tunnel & 0.8 \\
9 & Outlet slope of the emptying tunnel & 0.2 \\
10 & Emptying tunnel gate & 0.2 \\
\hline
\end{tabular}

TABLE 5: Probability distribution parameters for failure duration of release structures.

\begin{tabular}{|c|c|c|c|c|}
\hline \multirow{2}{*}{ Release structure } & \multirow{2}{*}{ Scenarios causing failure of release structures } & \multicolumn{3}{|c|}{ Failure duration $(\mathrm{d})$} \\
\hline & & $T_{\min }$ & $T_{\mathrm{mlv}}$ & $T_{\max }$ \\
\hline \multirow{2}{*}{ Spillway } & Seismic landslide of spillway slope & 2 & 3.5 & 5 \\
\hline & Gate failure & 1 & 1.5 & 2 \\
\hline \multirow{3}{*}{ Flood discharging tunnel } & Seismic landslide of inlet slope & 3 & 5 & 7 \\
\hline & Seismic landslide of outlet slope & 2 & 3.5 & 5 \\
\hline & Gate failure & 1 & 1.5 & 2 \\
\hline \multirow{2}{*}{ Power station diversion tunnel } & Seismic landslide of inlet slope & 3 & 5 & 7 \\
\hline & Seismic landslide of outlet slope & 2 & 3.5 & 5 \\
\hline \multirow{3}{*}{ Emptying tunnel } & Seismic landslide of inlet slope & 7 & 11 & 15 \\
\hline & Seismic landslide of outlet slope & 2 & 3.5 & 5 \\
\hline & Gate failure & 3 & 5 & 7 \\
\hline
\end{tabular}




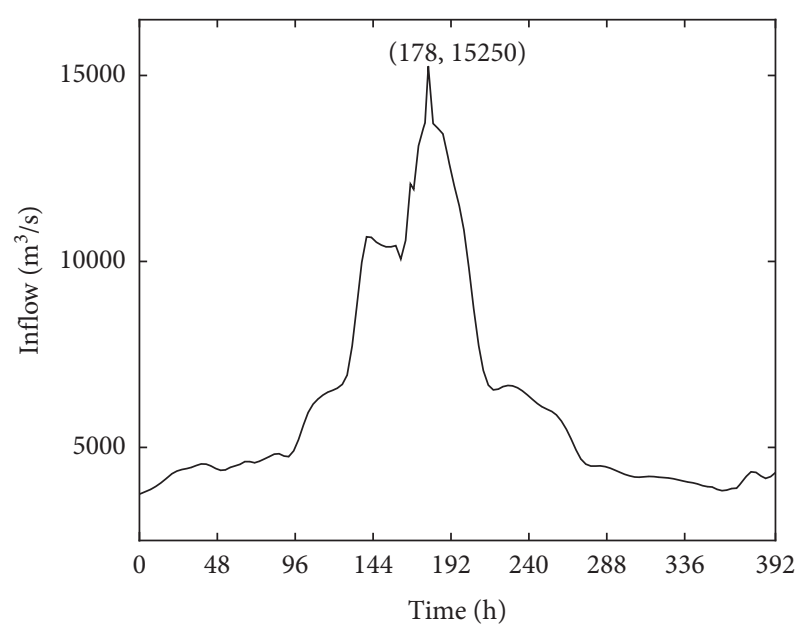

Figure 7: The maximum design flood hydrograph at the PBG dam site.

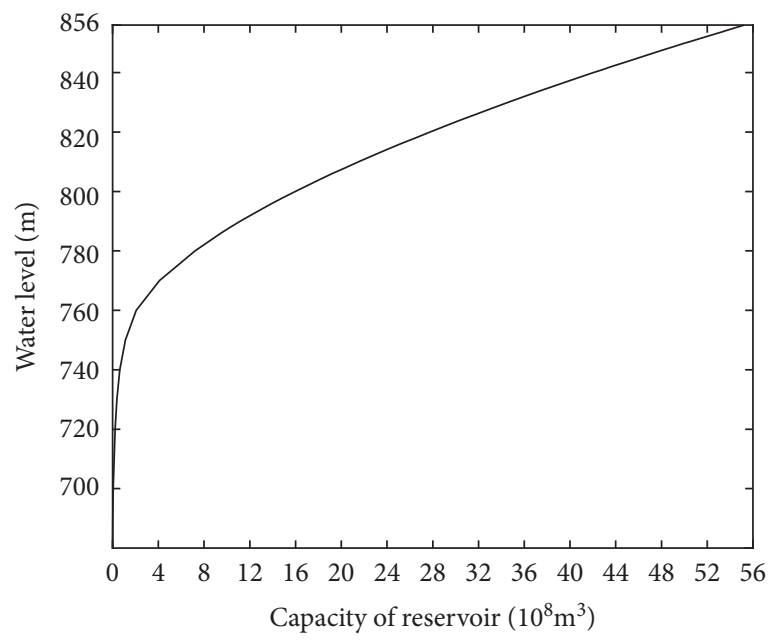

FIGURE 8: The water level-storage capacity curve for the PBG dam.

failure is assumed to be uniformly distributed (referred to as Case I), the overtopping risk of the PBG dam is analyzed using the Bayesian network model (as shown in Figure 6) with the model quantification results presented in Section 3. The GeNIe software [38] is used to evaluate the Bayesian network model. Figure 11(a) presents the result of the overtopping risk analysis for Case I. The probability of the dam overtopping is about $10 \%$ considering the influence of failure durations of the release structures.

The intermediate nodes in Figure 11(a) show the probability distributions of failure duration of the release structures affected by multiple landslides and gate failure, which are determined in terms of the uniformly distributed failure duration related to a landslide or gate failure, as well as the probabilities of the combinations of the landslides and gate failure. It is observed that the probabilities that spillway, flood discharging tunnel, power station diversion tunnel, and emptying tunnel do not fail are $12.25 \%, 2.50 \%, 1.75 \%$, and $12.80 \%$, respectively. The average failure durations for each release structure are $2.62 \mathrm{~d}, 4.13 \mathrm{~d}, 4.41 \mathrm{~d}$, and $9.12 \mathrm{~d}$, respectively. The standard deviations of failure durations are $1.44 \mathrm{~d}, 1.46 \mathrm{~d}, 1.40 \mathrm{~d}$, and $4.45 \mathrm{~d}$, respectively.

A sensitivity analysis is carried out to investigate the impact of each bottom node (i.e., the respective slope and gate) in the Bayesian network model on the dam overtopping risk for Case I. With the Bayesian network model shown in Figure 11(a) as a reference point, each bottom node is assigned, in turn, a probability of 1 and 0 , respectively, for being in the "failure" state, keeping the remaining nodes in their existing state and the resulting changes in the probability of dam overtopping are calculated. The sensitivity of dam overtopping risk to the bottom nodes is computed by normalizing the respective change in the probability of dam overtopping over the total change (i.e., sum of the changes in the probability of dam overtopping from each bottom node) and is presented in Figure 12(a). Since the spillway and flood discharging tunnel are major release structures for the PBG dam and the failure durations of both release structures related to seismic landslides are relatively long, the changes in failure probability of spillway slope and inlet slope of flood discharging tunnel have the greatest impacts on the dam overtopping risk. The effects of the changes in failure probability of the gates are minor as the failure durations of the release structures related to gate failure are relatively short.

Figure 11(b) shows the result of the overtopping risk analysis for Case II where the probability distribution of failure duration of release structure related to a landslide or gate failure is assumed to be triangularly distributed. The corresponding model quantification is presented in Section 3. The probability distributions of failure duration of the release structures affected by multiple landslides and gate failure are shown in the intermediate nodes in Figure 11(b). The probabilities that spillway, flood discharging tunnel, power station diversion tunnel, and emptying tunnel do not fail are $12.25 \%, 2.50 \%, 1.75 \%$, and $12.80 \%$, respectively. The average failure durations for each release structure are $2.63 \mathrm{~d}, 4.11 \mathrm{~d}, 4.43 \mathrm{~d}$, and $9.07 \mathrm{~d}$, respectively. The standard deviations of failure durations are $1.36 \mathrm{~d}, 1.28 \mathrm{~d}, 1.18 \mathrm{~d}$, and $4.17 \mathrm{~d}$, respectively. The probability of the dam overtopping is about $7 \%$ considering the influence of failure durations of the release structures. It is shown that the overtopping risk of the PBG dam is not sensitive to the probability distribution type of failure duration by comparing the computational results for Case I and Case II. The sensitivity analysis also reveals that the effects of the changes in failure probability of spillway slope and inlet slope of flood discharging tunnel on the dam overtopping risk are predominant and those of the gates are minor.

In order to investigate the effect of the failure duration of each individual release structure on the dam overtopping risk, the probabilities of dam overtopping corresponding to the failure duration of $0 \mathrm{~d}, 1 \mathrm{~d}, \ldots, 16 \mathrm{~d}$ for each individual release structure (keeping the failure durations of the remaining release structures in their existing probability distributions) are calculated and are shown in Figure 13. It can be seen that the probabilities of dam overtopping increase with the failure duration of each individual release structure. The probabilities of dam overtopping keep 


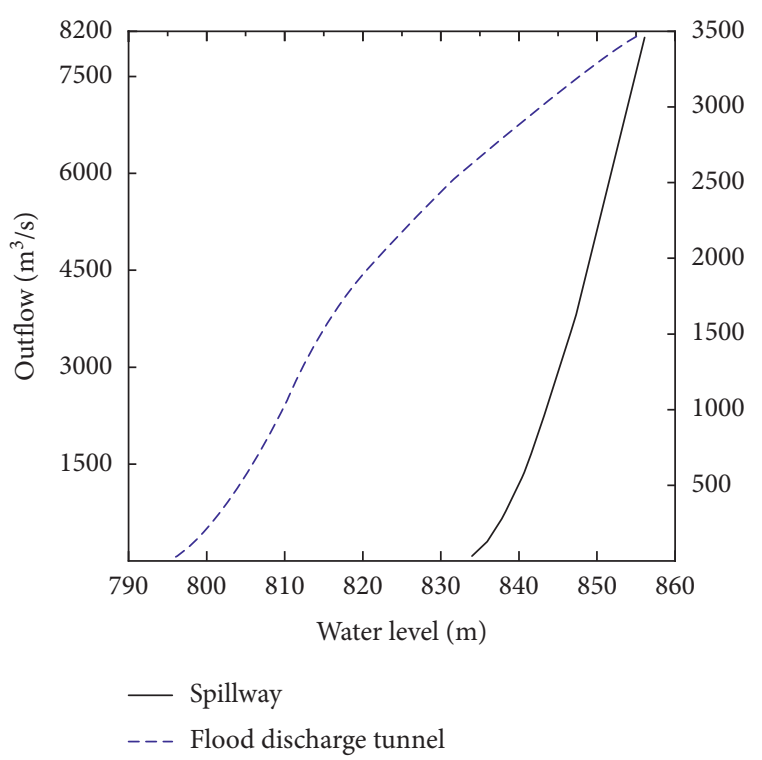

(a)

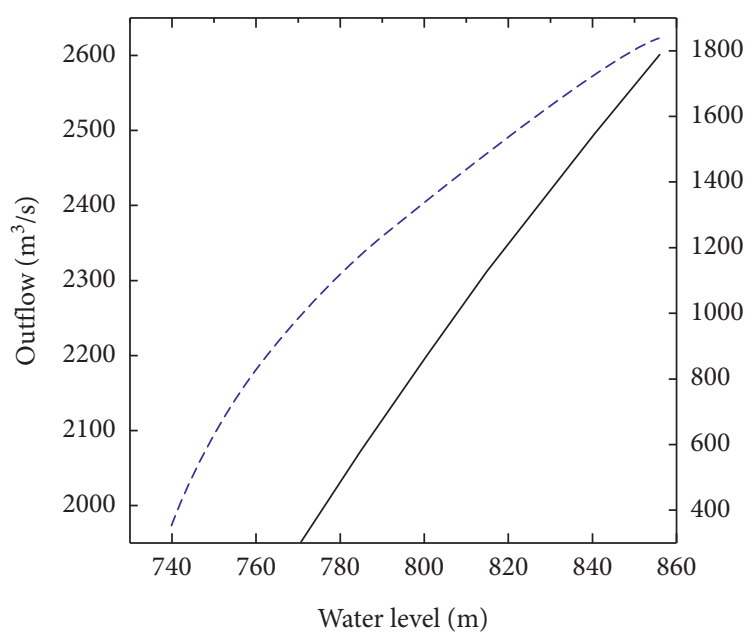

_- Power generation water diversion system --- Emptying tunnel

(b)

FIGURE 9: The discharge curves for release structures of the PBG hydropower station.

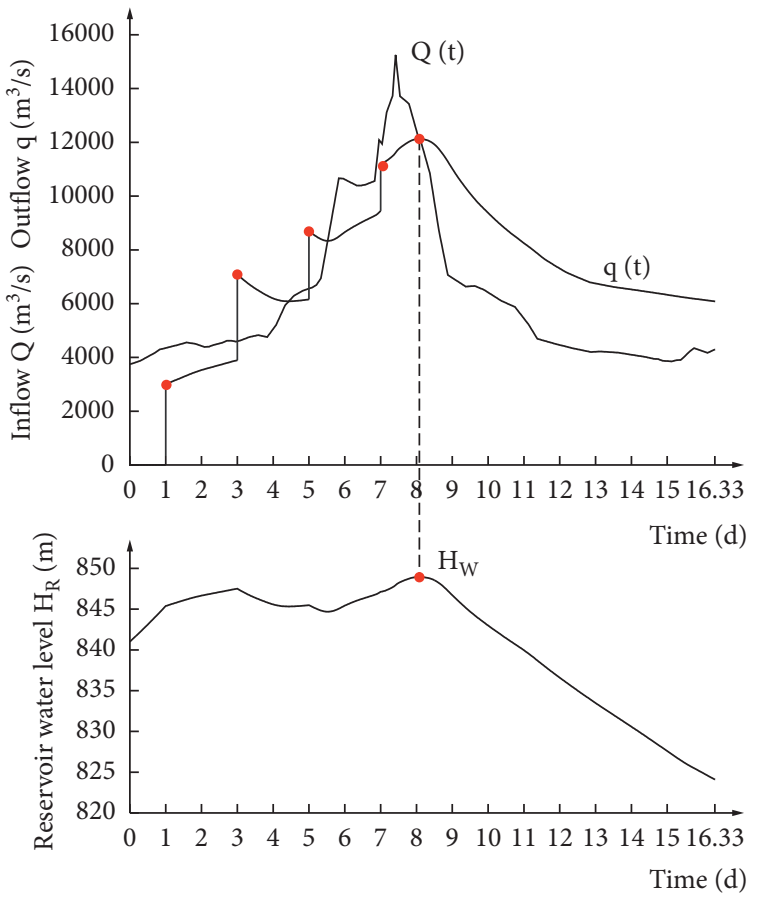

(a)

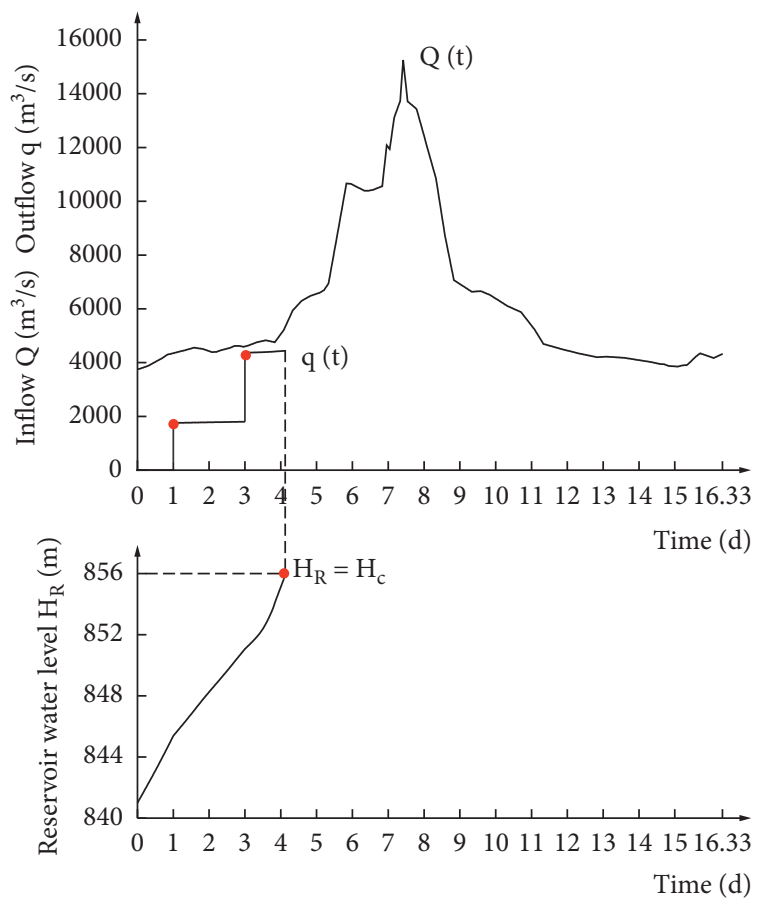

(b)

Figure 10: Typical results of reservoir routing for the PBG dam.

unchanged when the failure duration is greater than 8 days, since it is assumed that the release structures fail due to a severe earthquake when the flood begins to enter the reservoir and the flood flow decreases after 8 days. The increase in the failure duration of the spillway affects the dam overtopping risk quite significantly. When the failure duration of the spillway is less than 4 days, the corresponding dam overtopping risk is quite small, the maximum probability of dam overtopping is $8.1 \times 10^{-5}$ (Case II). However, when the failure duration of the spillway reaches 4 days, the probability of dam overtopping drastically rises to about $50 \%$. After then, the probability of dam overtopping continues to rapidly increase with the failure duration of the spillway. The probability of dam overtopping achieves the 


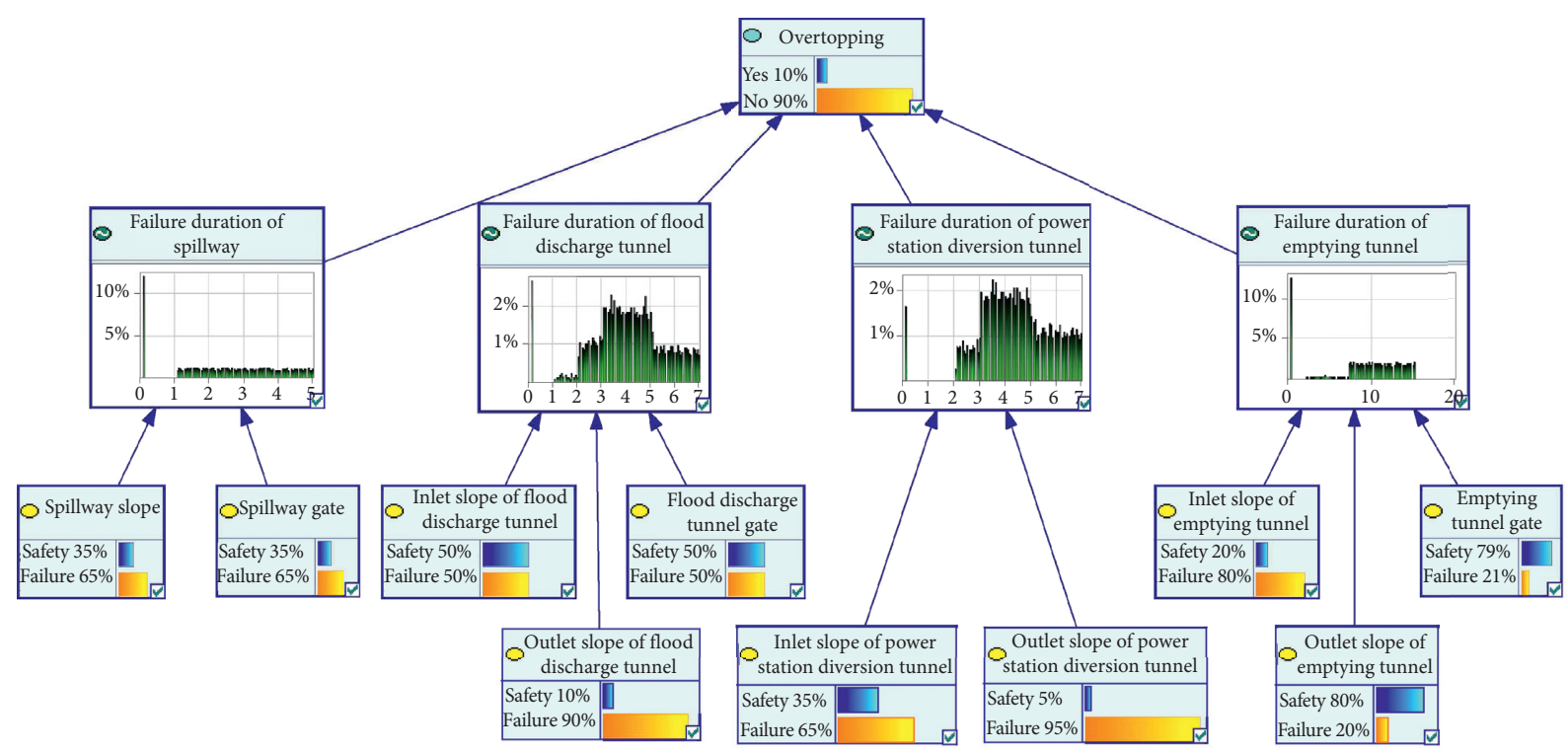

(a)

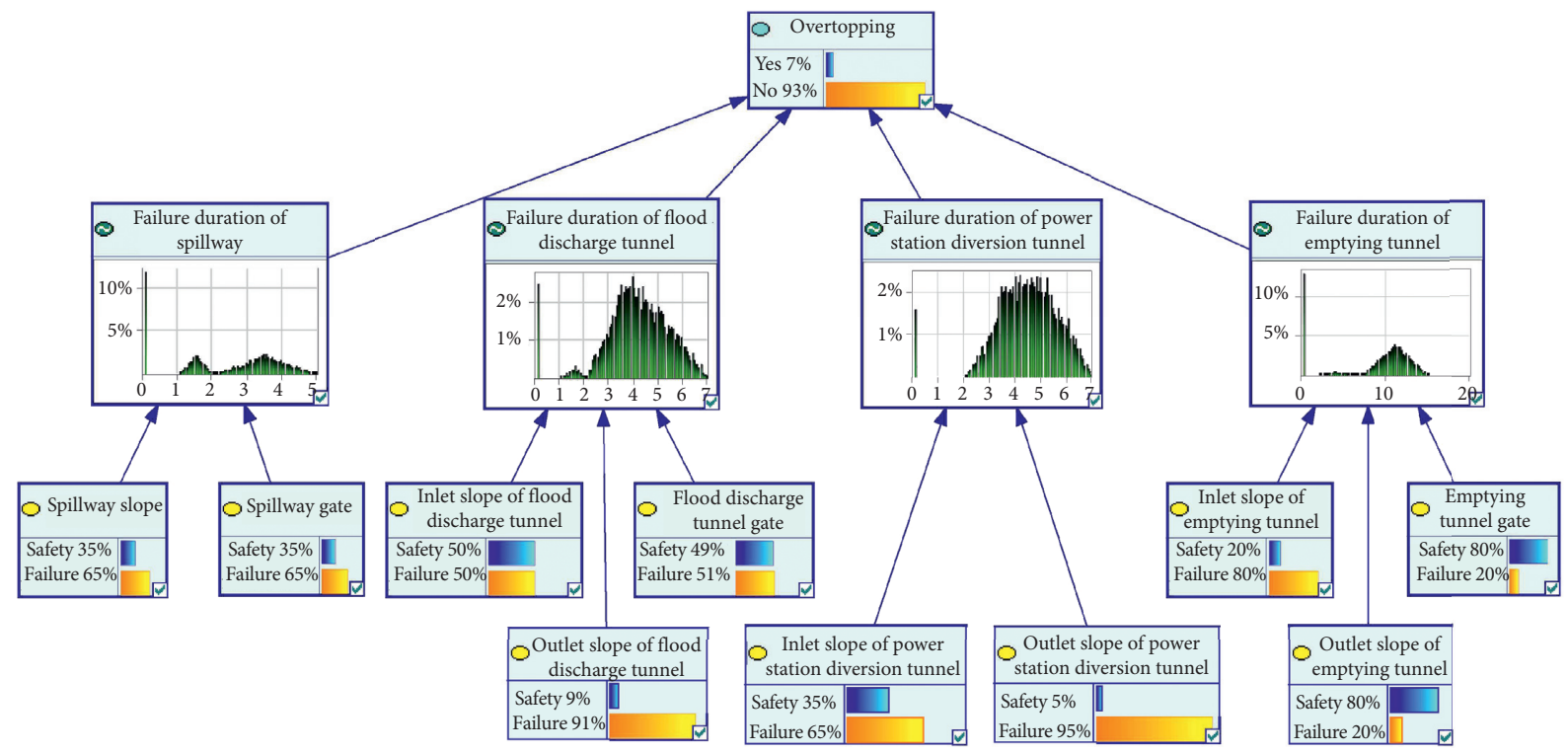

(b)

FIGURE 11: Results of overtopping risk analysis for different probability distributions of failure duration of release structure related to a landslide or gate failure: (a) case I, uniformly distributed failure duration, and (b) case II, triangularly distributed failure duration.

maximum value of about $96 \%$ when the failure duration is 8 days. The effect of the increase in the failure duration of the flood discharging tunnel on the dam overtopping risk is fairly important. When the failure duration of the flood discharging tunnel reaches 4 days, the probability of dam overtopping jumps form $3.5 \times 10^{-4}$ to $13.4 \%$ and remains constant until the failure duration reaches 8 days, the corresponding probability of dam overtopping sharply increases to $53.5 \%$ (Case II). The influences of the increase in the failure durations of the power station diversion tunnel and emptying tunnel on the dam overtopping risk are relatively small compared to the spillway and flood discharging tunnel.

\section{Conclusions}

Overtopping is one of the main causes of earth dam break. For modern high earth dams, sufficient safety margin is considered in the designs of flood discharge capacity and dam crest elevation to prevent flood overtopping. However, for the earth dams located in areas with intensive seismicity, there is a possible scenario that the release structures fail due to a severe earthquake when the flood begins to enter the reservoir. Thus, it is desirable to investigate the influence of failure duration of release structures on dam overtopping risk. For overtopping risk analysis of earth dams considering effects of failure duration of release structures, a Bayesian 


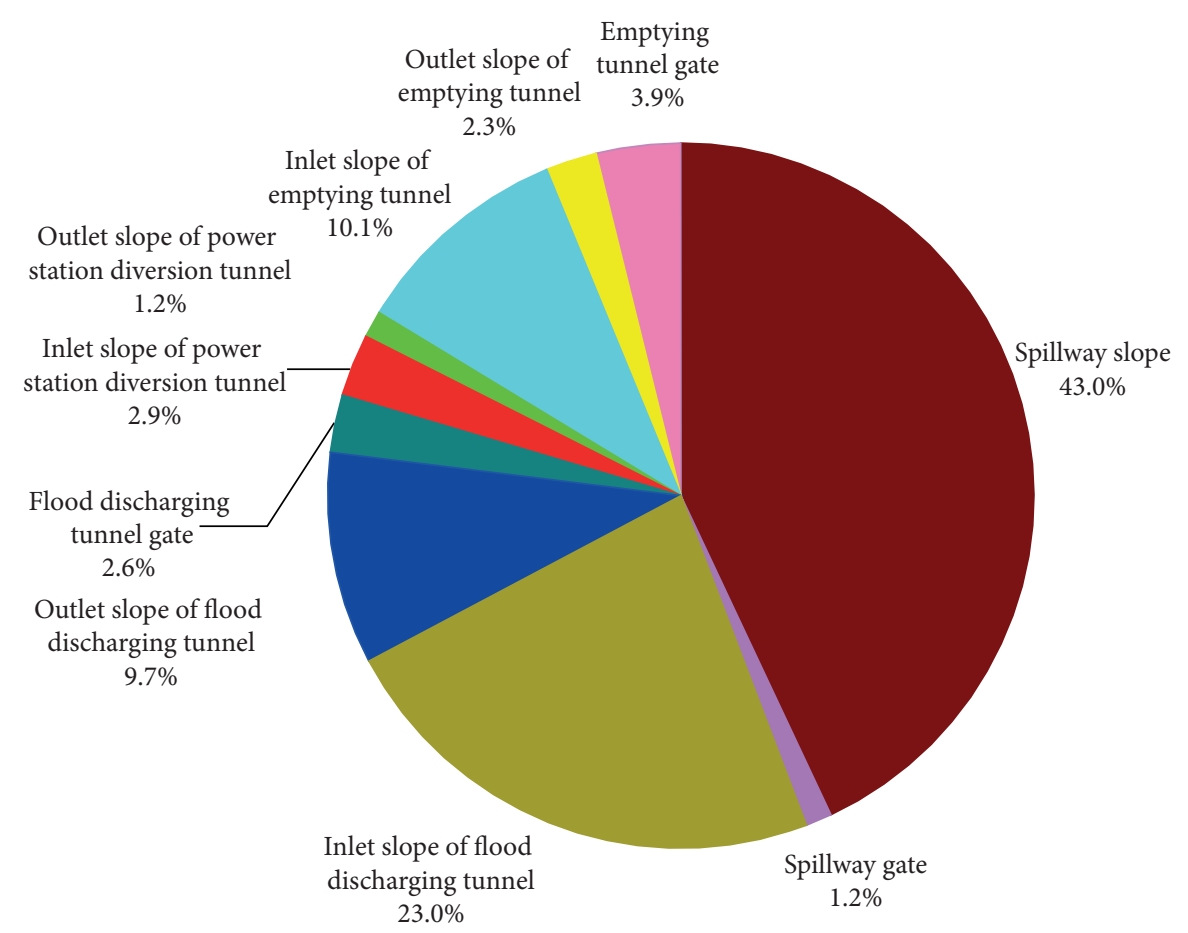

(a)

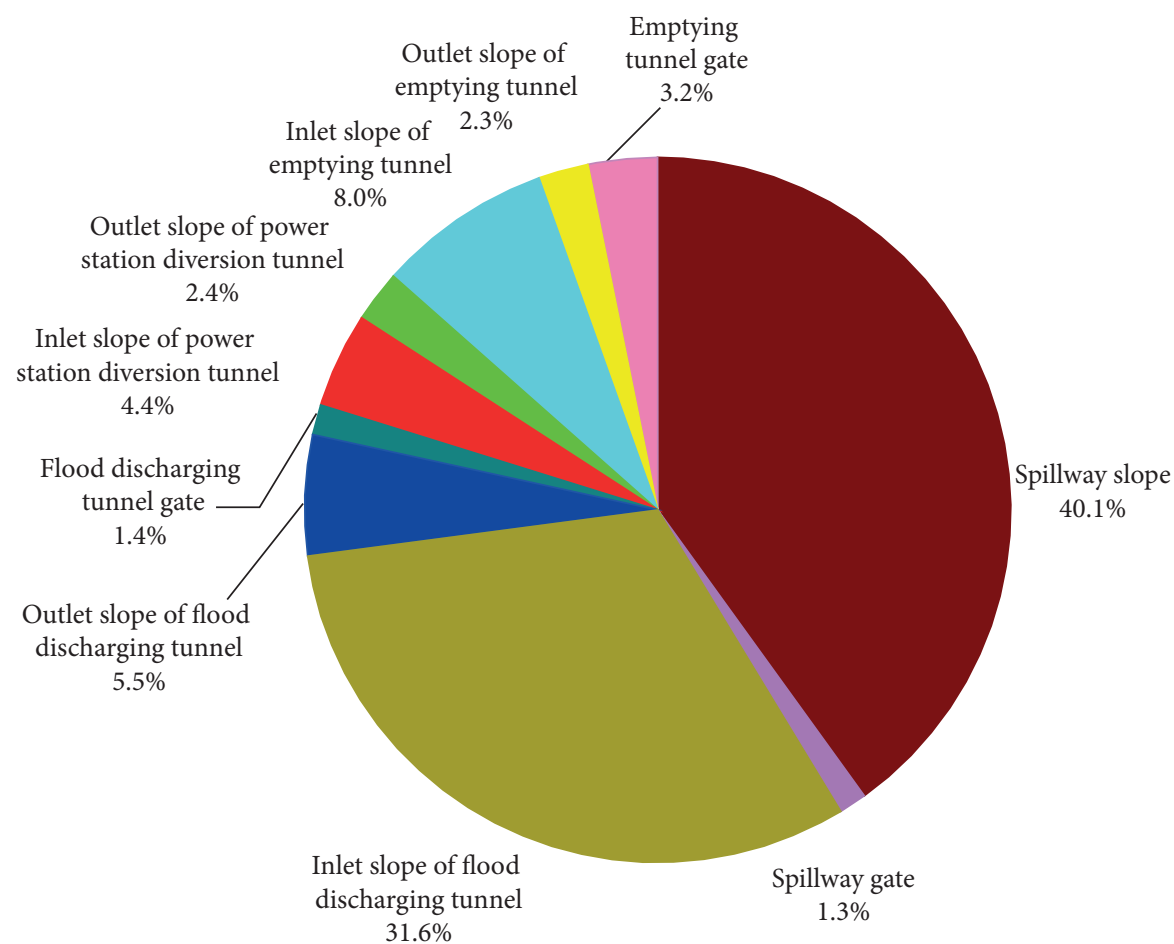

(b)

FIGURE 12: Results of sensitivity analysis for the impact of the change in failure probability of each bottom node on the dam overtopping risk for (a) case I and (b) case II.

network model and methods for model quantification are proposed.

As a case study, the overtopping risk of the PBG earthrockfill dam was analyzed. The spillway and flood discharging tunnel are critical release structures which dominate the dam overtopping risk. It is found that the dam overtopping risk is most sensitive to the failure duration of the spillway. The probability of dam overtopping is practically negligible when the failure duration of the spillway is less than 4 days whereas the dam overtopping risk drastically 

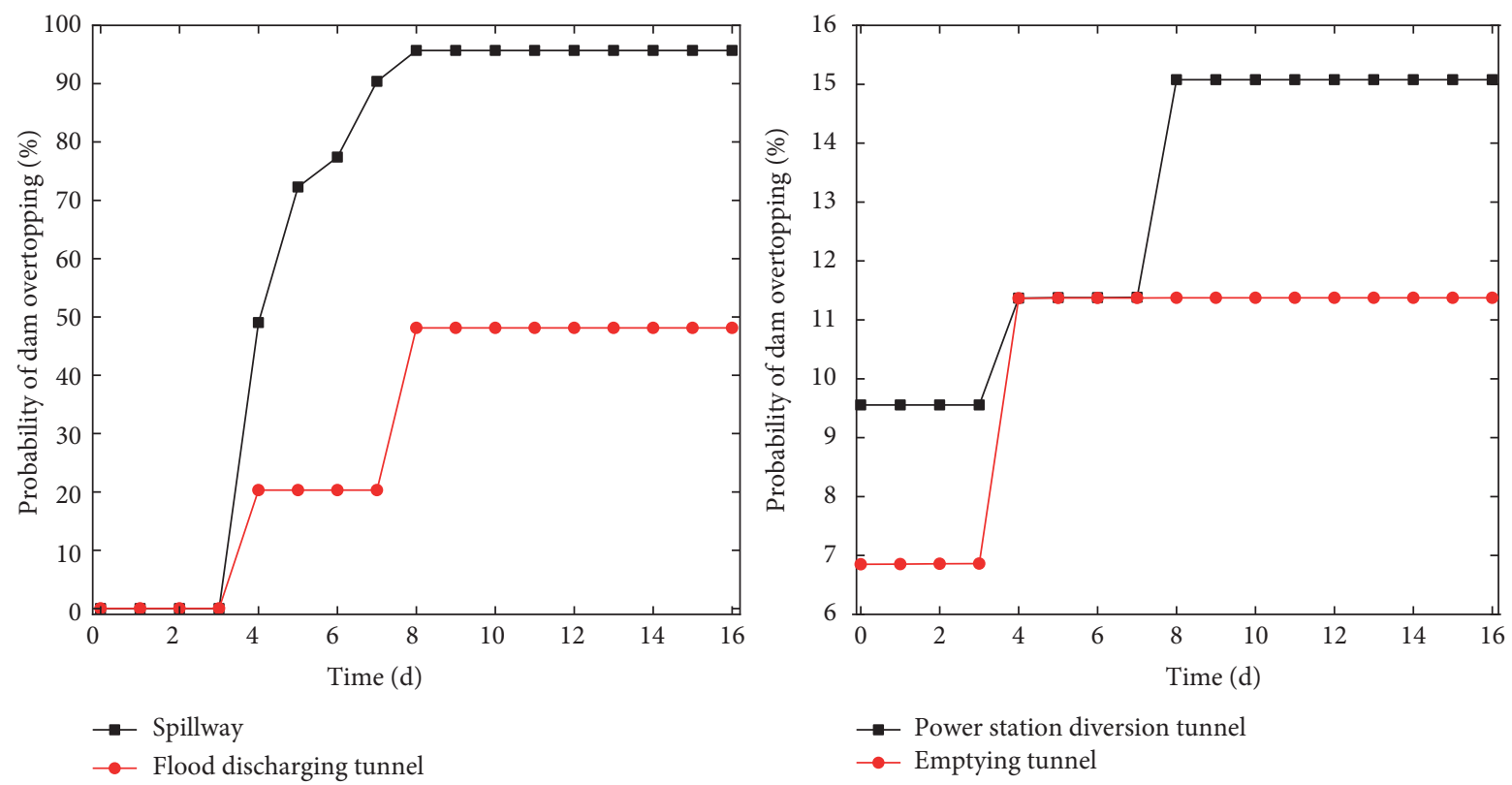

(a)
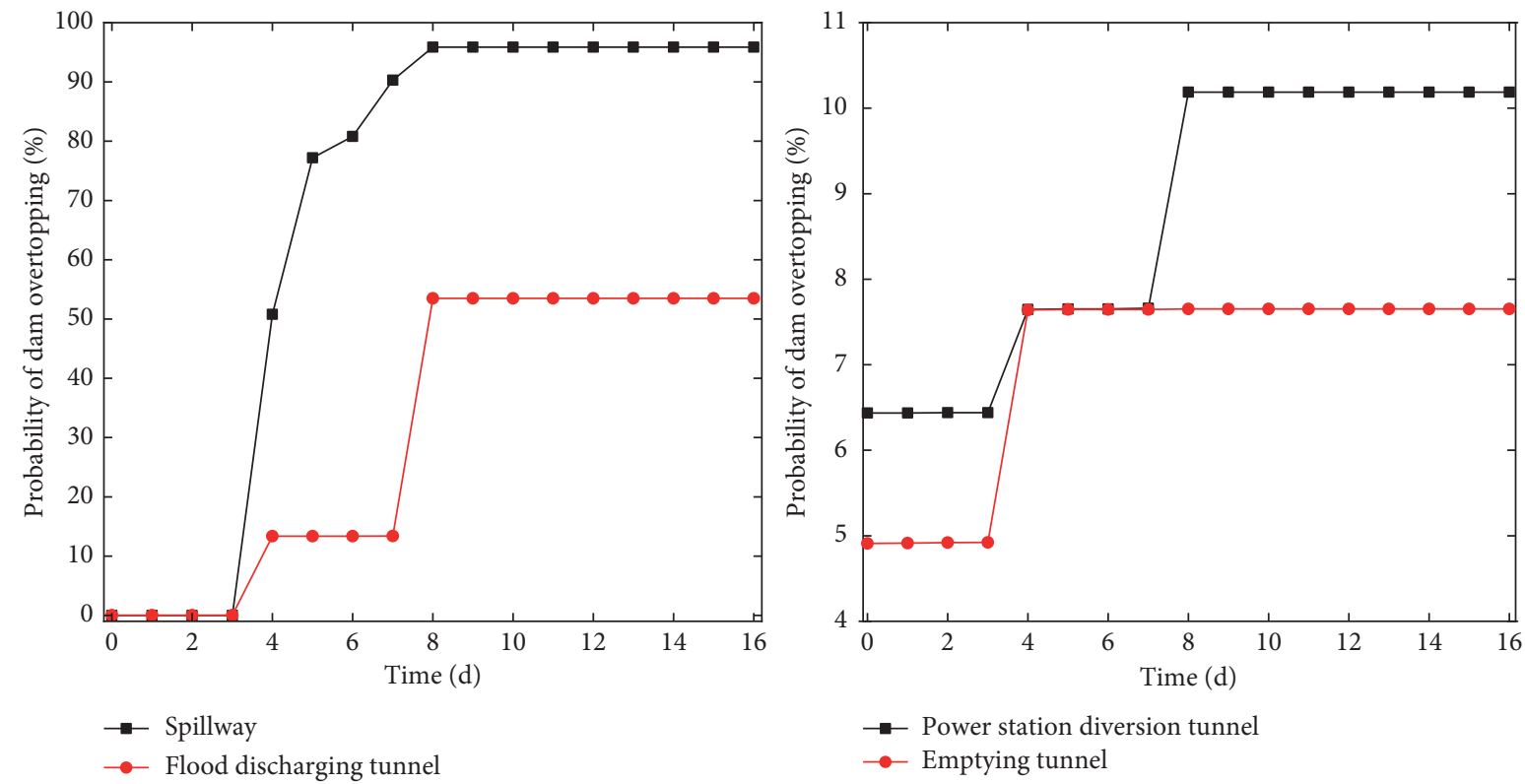

(b)

FIGURE 13: Variation of the probability of dam overtopping with the failure duration of each individual release structure for (a) case I and (b) case II.

rises to an unacceptable level when the failure duration of the spillway reaches 4 days. It implies that the tolerable failure duration of the spillway is approximately 3 days and intensive efforts have to be made to timely recover the discharge capability of the spillway for eliminating overtopping risk. For earth dams which may induce catastrophic consequences, extremely hazardous scenarios (such as the one considered in this study) which could occur and threaten dam safety during a long operational period of dams need to be considered.

The case study suggests that the proposed methodology could be helpful to analyze the influences of possible failure durations of release structures on dam overtopping risk and could facilitate preparation for emergency plans. For improving the proposed methodology, future works may be focused on the scheme for effectively eliciting and combining expert estimations of the probability distribution of failure duration of release structure as well as the efficient computation of reservoir routing considering failure duration of release structure.

\section{Data Availability}

The data used to support the findings of this study are available from the corresponding author upon request. 


\section{Conflicts of Interest}

The authors declare that they have no conflicts of interest.

\section{Acknowledgments}

Financial support provided by the National Key R\&D Program of China (no. 2018YFC0407103) is gratefully acknowledged.

\section{References}

[1] C.-X. Mo, G.-Y. Mo, Q. Yang, Y.-L. Ruan, Q.-L. Jiang, and J.-L. Jin, "A quantitative model for danger degree evaluation of staged operation of earth dam reservoir in flood season and its application," Water Science and Engineering, vol. 11, no. 1, pp. 81-87, 2018.

[2] Y. Luo, L. Chen, M. Xu, and J. Huang, "Breaking mode of cohesive homogeneous earth-rock-fill dam by overtopping flow," Natural Hazards, vol. 74, no. 2, pp. 527-540, 2014.

[3] Q. Zhong, S. Chen, and Z. Deng, "A simplified physicallybased model for core dam overtopping breach," Engineering Failure Analysis, vol. 90, pp. 141-155, 2018.

[4] Y. Xiang, Z. Wang, H. Yuan, C. Liu, and M. Yang, "Analysis of warning instance for typical emergent events of earth-rock dam under disaster environment," Disaster Advances, vol. 6, pp. 27-32, 2013.

[5] R. Moran and M. A. Toledo, "Research into protection of rockfill dams from overtopping using rockfill downstream toes," Canadian Journal of Civil Engineering, vol. 38, no. 12, pp. 1314-1326, 2011.

[6] S. Kostecki and J. Machajski, "Assessing reservoir operating requirements in changing hydrological conditions: a case study of mietków dam," Polish Journal of Environmental Studies, vol. 28, no. 1, pp. 177-185, 2019.

[7] Z. Liang, H. Huang, L. Cheng, Y. Hu, J. Yang, and T. Tang, "Safety assessment for dams of the cascade reservoirs system of Lancang River in extreme situations," Stochastic Environmental Research and Risk Assessment, vol. 31, no. 9, pp. 2459-2469, 2017.

[8] E. M. Michailidi and B. Bacchi, "Dealing with uncertainty in the probability of overtopping of a flood mitigation dam," Hydrology and Earth System Sciences, vol. 21, no. 5, pp. 2497-2507, 2017.

[9] T. Erdik, J. Duricic, and P. H. A. J. M. van Gelder, "The probabilistic assessment of overtopping reliability on akyayik dam," KSCE Journal of Civil Engineering, vol. 17, no. 7, pp. 1810-1819, 2013.

[10] B.-S. Lee and G. J.-Y. You, “An assessment of long-term overtopping risk and optimal termination time of dam under climate change," Journal of Environmental Management, vol. 121, pp. 57-71, 2013.

[11] E. Goodarzi, M. Mirzaei, and M. Ziaei, "Evaluation of dam overtopping risk based on univariate and bivariate flood frequency analyses," Canadian Journal of Civil Engineering, vol. 39, no. 4, pp. 374-387, 2012.

[12] Y. Sun, H. Chang, Z. Miao, and D. Zhong, "Solution method of overtopping risk model for earth dams," Safety Science, vol. 50, no. 9, pp. 1906-1912, 2012.

[13] Y.-C. Hsu, Y.-K. Tung, and J.-T. Kuo, "Evaluation of dam overtopping probability induced by flood and wind," Stochastic Environmental Research and Risk Assessment, vol. 25, no. 1, pp. 35-49, 2011.
[14] S. Jiang, "Application of stochastic differential equations in risk assessment for flood releases," Hydrological Sciences Journal, vol. 43, no. 3, pp. 349-360, 1998.

[15] Z. Liu, X. Xu, J. Cheng, T. Wen, and J. Niu, "Hydrological risk analysis of dam overtopping using bivariate statistical approach: a case study from Geheyan Reservoir, China," Stochastic Environmental Research and Risk Assessment, vol. 32, no. 9, pp. 2515-2525, 2018.

[16] A. C. Callau Poduje, A. Belli, and U. Haberlandt, "Dam risk assessment based on univariate versus bivariate statistical approaches: a case study for Argentina," Hydrological Sciences Journal, vol. 59, no. 12, pp. 2216-2232, 2014.

[17] A. I. Requena, L. Mediero, and L. Garrote, "A bivariate return period based on copulas for hydrologic dam design: accounting for reservoir routing in risk estimation," Hydrology and Earth System Sciences, vol. 17, no. 8, pp. 3023-3038, 2013.

[18] A. Sharafati and H. M. Azamathulla, "Assessment of dam overtopping reliability using sufi based overtopping threshold curve," Water Resources Management, vol. 32, no. 7, pp. 2369-2383, 2018.

[19] J.-T. Kuo, B.-C. Yen, Y.-C. Hsu, and H.-F. Lin, "Risk analysis for dam overtopping-Feitsui reservoir as a case study," Journal of Hydraulic Engineering, vol. 133, no. 8, pp. 955-963, 2007.

[20] H.-H. Kwon and Y.-I. Moon, "Improvement of overtopping risk evaluations using probabilistic concepts for existing dams," Stochastic Environmental Research and Risk Assessment, vol. 20, no. 4, pp. 223-237, 2006.

[21] C. Q. Li, W. Wang, and S. Wang, "Maximum-entropy Monte Carlo method for the evaluation of dam overtopping probability," Disaster Advances, vol. 5, no. 4, pp. 1143-1147, 2012.

[22] Y. Chen and P. Lin, "Bayesian network of risk assessment for a super-large dam exposed to multiple natural risk sources," Stochastic Environmental Research and Risk Assessment, vol. 33, no. 2, pp. 581-592, 2019.

[23] F. Wang and Q. L. Zhang, "Systemic estimation of dam overtopping probability: bayesian networks approach," Journal of Infrastructure Systems, vol. 23, no. 2, pp. 1-12, 2017.

[24] N. Li, Y. Gu, and Z. Deng, "Nonuniform sparse data clustering cascade algorithm based on dynamic cumulative entropy," Mathematical Problems in Engineering, vol. 2016, Article ID 5707692, 10 pages, 2016.

[25] L. Shen, C. Xu, and L. Liu, "Interaction among controlling factors for landslides triggered by the 2008 Wenchuan, China Mw 7.9 earthquake," Frontiers of Earth Science, vol. 10, no. 2, pp. 264-273, 2016.

[26] Q. Xu, Y. Li, S. Zhang, and X. Dong, "Classification of largescale landslides induced by the 2008 Wenchuan earthquake, China," Environmental Earth Sciences, vol. 75, no. 1, pp. 1-12, 2016.

[27] D. Guo, C. He, C. Xu, and M. Hamada, "Analysis of the relations between slope failure distribution and seismic ground motion during the 2008 Wenchuan earthquake," Soil Dynamics and Earthquake Engineering, vol. 72, pp. 99-107, 2015.

[28] J. Chen, P. A. Zhong, M. L. Wang, F. L. Zhu, X. Y. Wan, and Y. Zhang, "A risk-based model for real-time flood control operation of a cascade reservoir system under emergency conditions," Water, vol. 10, no. 2, pp. 1-18, 2018.

[29] Z. Micovic, D. N. D. Hartford, M. G. Schaefer, and B. L. Barker, "A non-traditional approach to the analysis of flood hazard for dams," Stochastic Environmental Research and Risk Assessment, vol. 30, no. 2, pp. 559-581, 2016. 
[30] S. Zhang and Y. Tan, "Risk assessment of earth dam overtopping and its application research," Natural Hazards, vol. 74, no. 2, pp. 717-736, 2014.

[31] J.-T. Kuo, Y.-C. Hsu, Y.-K. Tung, K.-C. Yeh, and J.-D. Wu, "Dam overtopping risk assessment considering inspection program," Stochastic Environmental Research and Risk Assessment, vol. 22, no. 3, pp. 303-313, 2008.

[32] J. Wang, X. Gu, and T. Huang, "Using Bayesian networks in analyzing powerful earthquake disaster chains," Natural Hazards, vol. 68, no. 2, pp. 509-527, 2013.

[33] Q. Lu, P. Chen, B. M. Kim, J. Zheng, and J. Ji, "Probabilistic assessment of seismic stability of a rock slope by combining the simulation of stochastic ground motion with permanent displacement analysis," Engineering Geology, vol. 260, pp. 111, 2019.

[34] H. W. Huang, S. C. Wen, J. Zhang, F. Y. Chen, J. R. Martin, and H. Wang, "Reliability analysis of slope stability under seismic condition during a given exposure time," Landslides, vol. 15, no. 11, pp. 2303-2313, 2018.

[35] J. Huh and A. Haldar, "Seismic reliability of non-linear frames with PR connections using systematic RSM," Probabilistic Engineering Mechanics, vol. 17, no. 2, pp. 177-190, 2002.

[36] L. M. Zhang, Y. Xu, J. S. Jia, and C. Zhao, "Diagnosis of embankment dam distresses using Bayesian networks. Part I. Global-level characteristics based on a dam distress database," Canadian Geotechnical Journal, vol. 48, no. 11, pp. 1630-1644, 2011.

[37] H. D. Morris and J. S. Mark, Probability and Statistics, Pearson Press, New York, NY, USA, 4th edition, 2011.

[38] L. L. C. BayesFusion, GeNIe Modeler: User Manual, Version 2.2.1, BayesFusion, LLC, Pittsburgh, PA, USA, 2017. 